\title{
ORDENAÇÕES AFONSINAS: BREVE ANÁLISE SOB UMA PERSPECTIVA DE ACESSO À JUSTIÇA*
}

\author{
AFONSINE ORDINANCES: ANALYSIS UNDER A BRIEF PERSPECTIVE OF ACCESS TO JUSTICE
}

Gabriel Felipe Roqueto Riguetti*

\begin{abstract}
Resumo:
O presente estudo é uma breve análise das Ordenações Afonsinas por meio de uma perspectiva atual de Acesso à Justiça. Nesse sentido, algumas disposições legais daquele diploma serão tomadas como objeto de avaliação, verificando se tinham aptidão para incluir ou excluir os cidadãos do debate no âmbito jurisdicional. Para tanto, dialogar-se-á com a sociologia e a história, visando a traçar um panorama geral da sociedade portuguesa do século XV e sua acessibilidade ao Poder Judiciário.

Palavras-chave: Ordenações Afonsinas. Dispositivos. Século XV. Sociedade Portuguesa. Acesso à justiça.

Abstract:

The present study is a brief analysis of the Afonsine Ordinances trough a current perspective of access to Justice. In this sense, some of the legal provisions of that Ordinances will be taken as the object of analysis, v.g. if it had suitability to include or to exclude citizens of the debate within court. Therefore, a necessary dialog with sociology and history in order to draw a general picture of the $15^{\text {th }}$ century Portuguese society and its accessibility to the Court was made.
\end{abstract}

Keywords: Afonsine Ordinance. Devices. 15 ${ }^{\text {th }}$ Century. Portuguese Society. Access to Justice.

\section{Introdução}

O estudo da História tem, sem dúvida nenhuma, grande relevância para as ciências humanas em especial e para a sociedade em geral. Ao se perguntarem sobre o porquê de uma abordagem histórica dos fatos, José Rogério Cruz e Tucci e Luiz Carlos de Azevedo, em introdução da obra sobre o Processo Civil nos tempos de Roma, definem quatro grandes motivos para justificar essa importância. ${ }^{1}$

Artigo originalmente apresentado como trabalho final da disciplina "História do Processo Canônico Romano, Canônico e Lusitano: Monumentos Legislativos e Instituições Processuais", oferecida no primeiro semestre de 2012 pelo Professor Titular José Rogério Cruz e Tucci no curso de Pós-Graduação strictu sensu da Faculdade de Direito da Universidade de São Paulo.

** Graduado em Direito pela Faculdade de Direito da Universidade de São Paulo. Mestrando em Direito pela mesma instituição, com orientação do Professor Titular José Roberto dos Santos Bedaque. E-mail: gabriel. riguetti@usp.br.

1 Cfr. AZEVEDO, Luiz Carlos de; CRUZ E TUCCI, José Rogério. Lições de história do processo civil romano. São Paulo: Revista dos Tribunais, 1996. p. 19-25. 
O primeiro e mais concreto deles é que os homens e a sociedade vivenciam a cada instante a história. Ela permeia a religião, os hábitos, a cultura, a arquitetura de uma cidade, enfim, ela está presente a todo o momento no viver dos indivíduos, no desenvolver das sociedades, mesmo que estes não se deem conta de tal fato.

Nota-se, portanto, que o homem e suas relações são, de fato, fruto de uma bagagem histórica muito grande. Apresentam-se como produto da sedimentação dos tempos e, certamente, será substrato sobre o qual florescerá o homem de amanhã.

Consequência disso é a pertinente observação dos citados autores de que a história não é formada por compartimentos estanques. Não há linhas divisórias separando o presente e o passado. É, ao contrário, um constante movimentar, um incansável caminhar adiante, tratando-se de "imagens vivas, que por alguma razão não estavam expostas à luz, mas que agora estão a fornecer maiores subsídios à pesquisa e ao conhecimento, possibilitando a maior compreensão da realidade presente". ${ }^{2}$

E por essa razão, a História, tomada por uma perspectiva crítica, mediante uma séria e dedicada pesquisa, poderá fornecer ao estudioso e à sociedade contemporânea a ele respostas para determinados comportamentos, para certas tendências que, em realidade, nada mais são do que, como já afirmado, frutos dos fenômenos e acontecimentos ocorridos no passado. Em outras palavras, a leitura dos acontecimentos dos fatos pretéritos poderá fornecer àquele que se debruça sobre o passado explicações - e muitas vezes soluções - para os problemas hodiernos, sendo, pois, um interessante instrumento social.

É justamente por tudo isso que não se pode conceber o estudo histórico como um mecânico método de armazenamento de datas e nomes. Ao contrário, a história deverá ser analisada por uma perspectiva concreta, viva, abandonando-se a velha sistemática da narrativa enfadonha e repetitiva. Caso assim não se proceda, o estudo histórico estará fadado à inutilidade, tornando-se, pois, uma dedicação estéril.

Desse modo, o presente trabalho visa a analisar as ordenações portuguesas não como um conjunto de normas empoeiradas, como se relíquias fossem em uma vitrine de um antiquário, narrando-se esse ou aquele instituto como algo perdido no tempo e sem contato nenhum com a realidade atual. Distante disso buscar-se-á adotar uma perspectiva capaz de identificar inúmeros fatores e elementos presentes hodiernamente no processo civil, mostrando que muito do que se julga superado é, ainda hoje, existente na realidade da processualística.

Para tanto, far-se-á uma abordagem interdisciplinar, utilizando-se de informações das áreas da economia, da sociologia e da educação. Acredita-se que esse

2 AZEVEDO, Luiz Carlos de; CRUZ E TUCCI, José Rogério. Lições de história do processo civil romano. São Paulo: Revista dos Tribunais, 1996. p. 20. 
intercâmbio e diálogo poderá enriquecer o que aqui se propõe: avaliar os pontos favoráveis e desfavoráveis das ordenações ao Acesso à Justiça.

Antes de tecer alguns breves comentários sobre o que se entende por Acesso à Justiça, algumas observações que se julga de extrema importância deverão ser aqui expostas.

A primeira delas é que o estudo histórico deve ser realizado com muito cuidado. Avaliações, análises e principalmente valorações de fenômenos pretéritos não devem ser feitos com a mentalidade existente nos dias atuais, isto é, deve-se despir de conceitos e interpretações como se hoje fosse. Em outros termos, deve o estudioso tentar se colocar nas circunstâncias existentes no momento objeto do estudo, sob pena de se concluírem coisas inexatas, equivocadas e, por que não, injustas.

Desse modo, a título de exemplo, concluir que os portugueses cometeram um erro imperdoável ao identificar o Brasil como uma ilha, batizando-o de Ilha de Vera Cruz, é no mínimo injusto, vez que não dispunham das tecnologias de satélite usadas atualmente. Pode parecer infantil o exemplo dado. Contudo, equívocos de tal ordem são mais frequentes do que se imagina. ${ }^{3}$

Além dessa observação de ordem metodológica, devem-se fazer algumas ressalvas de natureza subjetiva. Não se pretende fazer um estudo exauriente, seja em extensão seja em profundidade. E isso nem seria possível pelas próprias limitações intelectuais encontradas pelo autor. Como se adiantou alhures tentar-se-á analisar as ordenações por meio de uma visão interdisciplinar e, definitivamente, não se possui completo domínio da economia, sociologia e demais disciplinas aqui utilizadas como subsídios. Ademais, a limitação de tempo e espaço também se consubstanciam em empecilhos para esse esgotamento.

Logo, o que aqui se propõe - e tenta-se deixar consignado desde já- é que o presente trabalho analisará as Ordenações Afonsinas, verificando seus institutos favoráveis e desfavoráveis ao Acesso à Justiça sem que, com isso, necessite-se de conceitos específicos de cada um dos ramos científicos adotados.

Tais matérias, na realidade, servirão como auxiliares na constatação desse acesso, que, segundo posição aqui adotada, é conceito naturalmente interdisciplinar. Tal

\footnotetext{
Em interessante observação em texto dedicado à introdução ao estudo histórico na academia jurídica, MADEIRA, Hélcio Maciel França assim expõe o problema: “(...) ultrapassar os lindes temporais, em direção ao passado ou ao futuro, exige método histórico. Exige uma posição de estudo diferente, infreqüente nas disciplinas do curso jurídico. E as duas citadas adversidades - carência bibliográfica e inexperiência metodológica - fizeram do capítulo "introdução histórica", tão comum nas monografias finais, o mais depauperado". Cf. A história do direito. Disponível em: <http://helciomadeira.sites.uol.com.br/historia arquivos/hd001.htm>. Acesso em: 31 maio 2012.
} 
desiderato, com o desenvolver do tema e conceituação de Acesso à Justiça, ao final desse capítulo introdutório, ficará bem mais claro.

Passa-se então ao acesso em si.

\subsection{O acesso à justiça: conceito}

Os doutrinadores que melhor sistematizaram e conceituaram o Acesso à Justiça como um direito foram Mauro Cappelletti e Bryant Garth. Em obra destinada a ser introdução geral aos volumes produzidos pelo chamado 'Projeto Florença', que envolveu inúmeros países e seus respectivos sistemas jurídicos processuais, os dois autores identificam a dificuldade em se conceituar o Acesso à Justiça. Entretanto, assim o fazem da seguinte maneira: “A expressão 'acesso à Justiça' é reconhecidamente de difícil definição, mas serve para determinar duas finalidades básicas do sistema jurídico - o sistema pelo qual as pessoas podem reivindicar seus direitos e/ou resolver seus litígios sob o auspício do Estado. Primeiro o sistema deve ser igualmente acessível a todos; segundo, ele deve produzir resultados que sejam individual e socialmente justos". ${ }^{4}$

Dessa definição, podem-se extrair duas conclusões. A primeira é que o Acesso à Justiça, por estar relacionado ao fato de o sistema jurídico ser posto à disposição dos indivíduos para reivindicação dos seus direitos, começa antes mesmo do ingresso no Poder Judiciário. Desse modo, como se verá detalhadamente mais a frente, o Acesso à Justiça está intimamente ligado aos fatores subjetivos dos indivíduos componentes de uma sociedade, tais como educação, consciência jurídica, entre outros.

Por outro lado, o fato de seu conceito relacionar-se com a resolução dos conflitos, assegurando o direito àquele que faz jus, remete à ideia de que só se terá Acesso à Justiça se os resultados do processo forem os justos. E, como se esmiuçará adiante, tanto elementos externos (tempo e custas, por exemplo), como internos (formalidades), poderão obstar que o cidadão efetive seu direito no plano concreto.

Feita essa explanação, passa-se à análise individualizada de cada um desses elementos, tanto os pré como os pós Poder Judiciário.

\subsubsection{Elementos externos ao processo ou sociais}

Como foi anteriormente introduzido, para que os cidadãos possam buscar seus direitos por meios institucionais, isto é, por meio do processo, estes devem, antes de mais nada, conhecer os direitos existentes e a eles atribuídos. Há, portanto, barreiras

4 Cf. CAPPELlETTI, Mauro; GARTH, Bryant. Acesso à justiça. Trad. Ellen Gracie Northfleet. Porto Alegre: Antônio Fabris, 2002. p. 8. 
individuais e culturais a serem superadas para que as pessoas possam reivindicá-los, sendo esse momento anterior à apresentação do problema ao juiz. São impedimentos de natureza subjetiva.

Essas barreiras podem ser fruto de inúmeros fatores. Dentre eles destaca-se o acesso dos cidadãos ao sistema de ensino. A profusão da informação aos membros de uma sociedade é responsável direto por atribuir maior visão e capacidade críticas a eles.

Não se pode conceber, portanto, uma sociedade combativa, que reivindica seus direitos, sem que haja escolas e acesso aos seus postos. A informação e a difusão da cultura consubstanciam-se em elementos primordiais ao Acesso à Justiça.

Ademais, para a quebra da barreira cultural supra citada, primordial que o ensino oferecido - que deve abranger a maior parte da população, como se disse acima tenha qualidade. De nada adiantaria toda a população frequentar escolas se estas pouco ou nada se preocuparem com o conteúdo passado.

Além disso, não basta que os cidadãos tenham consciência de seus direitos. Outro elemento basilar para o Acesso à Justiça é o conhecimento da maneira correta de reivindicar aquilo que entende ser direito seu. Como é sabido, o processo é algo distante dos cidadãos de uma sociedade. Muitos conhecem aquilo que a ordem jurídica lhe assegura, mas não sabem sequer como iniciar a atividade estatal.

Corroborando o que foi dito até aqui, Mauro Cappelletti e Bryant Garth identificam que, mesmo que conheçam seus direitos, "as pessoas têm limitados conhecimentos a respeito da maneira de ajuizar uma demanda", fato que obsta por completo o Acesso à Justiça.

Dessa forma, sem conhecimentos processuais, os indivíduos são obrigados a consultar os advogados para suprirem essa lacuna. Surge ai mais um problema: a disposição para tal busca de ajuda e enfrentamento do trâmite institucional. Em muitos casos, especialmente em se tratando de pessoas menos favorecidas, o temor, o sentimento de intimidação, a postura exacerbadamente formal, enfim, o ambiente não habitual dos tribunais em geral causa afastamento e renitência dos cidadãos em procurar o poder judiciário. $^{6}$

Essa disposição, como bem observou os autores citados, é maior naqueles indivíduos por eles denominados 'habituais' do que em pessoas que eventualmente

CAPPELLETTI, Mauro; GARTH, Bryant. Acesso à justiça. Trad. Ellen Gracie Northfleet. Porto Alegre: Antônio Fabris, 2002. p. 23.

6 Tratando do tema, CAPPELLETTI, Mauro; GARTH, Bryant afirmam: “(...) há razões óbvias por que os litígios formais são considerados tão pouco atraentes. Procedimentos complicados, formalismo, ambientes que intimidam, como o dos tribunais, juízes e advogados, figuras tidas como opressoras, fazem com que o litigante se sinta perdido, um prisioneiro num mundo estranho". Acesso à Justiça. Trad. Ellen Gracie Northfleet. Porto Alegre: Antônio Fabris, 2002, p. 24. 
(ou nunca) acionam o poder do estado para a busca de seus direitos. Identificam com extrema precisão quatro vantagem daqueles sobre estes. São elas: "1) maior experiência com o Direito possibilita-lhes melhor planejamento do litígio; 2) o litigante habitual tem economia de escala, porque tem mais casos; 3) o litigante habitual tem oportunidades de desenvolver relações informais com os membros da instância decisora; 4) ele pode diluir os riscos da demanda por maior número de casos; e 5) pode testar estratégias com determinados casos, de modo a garantir expectativa mais favorável em relação a casos futuros". ${ }^{7}$

Não bastassem todos esses empecilhos subjetivos e culturais, há ainda que se levar em conta os obstáculos de natureza econômica. Nesse passo, as custas judiciais apresentam-se como um grande problema a ser superado. Indivíduos somente conseguirão buscar seus direitos pelos meios institucionais se conseguirem arcar com os gastos que esse método apresenta.

Além dos valores a serem despendidos a título de custas, há que se relevar os honorários dos advogados, problema este intrinsecamente relacionado com o óbice anterior: o não-conhecimento das vias processuais adequadas para reivindicação dos direitos.

Desse modo, por não conhecer os meios, necessita-se de um profissional com conhecimentos técnicos, que exige o dispêndio de dinheiro. Não havendo condições financeiras para tal, obstrui-se o Acesso à Justiça. A questão financeira é, pois, elemento primordial para essa temática.

Por fim, ainda no plano das barreiras extraprocessuais, encontra-se o fator tempo, intimamente ligado à barreira de natureza econômica. Sabe-se que a demora para o término processual é um inimigo dos cidadãos, principalmente quando se encontra em litígio um indivíduo menos abastado.

Citando as lições de Mauro Cappelletti e Bryant Garth: "Os efeitos dessa delonga, especialmente se considerados os índices de inflação, podem ser devastadores. Ela aumenta os custos para as partes e pressiona os economicamente fracos a abandonar suas causas, ou a aceitar acordos por valores muito inferiores àqueles a que teriam direito". 8

Logo, somados esses obstáculos culturais e econômicos, todos anteriores ao início do processo, forma-se o conjunto dos denominados elementos exteriores ao processo ou fatores sociais obstacularizadores do Acesso à Justiça.

CAPPELLETTI, Mauro; GARTH, Bryant. Acesso à justiça. Trad. Ellen Gracie Northfleet. Porto Alegre: Antônio Fabris, 2002. p. 25.

8 CAPPELlETTI, Mauro; GARTH, Bryant. Acesso à justiça. Trad. Ellen Gracie Northfleet. Porto Alegre: Antônio Fabris, 2002. p. 20. 
Ocorre, porém, que nem só os elementos extraprocessuais é que dificultam (ou até mesmo impedem) este acesso. Muitos fenômenos internos ao meio institucional de reivindicação de direitos concorrem para o levantamento de barreiras.

\subsubsection{Elementos processuais ou técnico-jurídicos}

Muitos são os fatores internos ao processo que dificultam o Acesso à Justiça. No entanto, para os fins propostos por esse trabalho, tomar-se-á apenas um como objeto de análise: o formalismo.

Umbilicalmente ligado com os demais problemas levantados, o formalismo, como se disse alhures, é um dos fatores de intimidação e consequente afastamento dos cidadãos da busca de seus direitos pela via judiciária. É um típico elemento que mina os ânimos e os interesses dos indivíduos pelo processo.

O formalismo, outrossim, está relacionado com a demasiada dilação do tempo processual. Processos dotados de muitas formalidades são naturalmente mais demorados. A obediência estrita às formas é certamente um comprometedor da celeridade almejada para esse método estatal de resolução de conflitos.

O mesmo formalismo é responsável pelo crescimento dos valores atribuídos aos litigantes. Processos formalistas têm seus custos elevados, favorecendo uma exclusão dos menos favorecidos ao cenário jurisdicional.

Toda essa problemática levantada, seja extra ou endoprocessual, traz elementos que estão umbilicalmente relacionados às áreas econômicas, sociológicas, pedagógicas, educacionais e, porque não, políticas, além, é claro, jurídicas.

É nesse sentido que foi dito anteriormente que a interdisciplinaridade, o diálogo entre direito e outras matérias, é instrumento essencial para análise dos problemas do Acesso à Justiça.

O presente trabalho se utilizará, portanto, dessas perspectivas para avaliar os institutos das ordenações afonsinas. Buscar-se-á, antes que se analise instituto por instituto individualmente, mapear as condições econômicas e culturais de Portugal nos séculos XV e VI para verificar se existiam ou não os obstáculos ao Acesso à Justiça, acima apontados.

Dito isso, fica clara a intenção aqui proposta. Contudo, ela pode parecer paradoxal à ressalva feita anteriormente, qual seja: a de não ser correta a avaliação e valoração de institutos do passado com visões hodiernas. Como é sabido, Mauro Cappelletti e Bryant Garth, realizaram seus estudos apenas no século passado. O 'Projeto Florença' estruturou-se sobre dados colhidos na segunda metade do século XX. Por outro lado, os portugueses das ordenações nem mesmo concebiam o processo como um ramo 
autônomo do Direito, ${ }^{9}$ concepção essa que somente foi existir no século XIX com a obra de Oskar Von Bülow. ${ }^{10}$ Tampouco conheciam os escopos sociais, políticos e jurídicos apontados pela doutrina atual. ${ }^{11}$ Aliás, nem sequer se pode afirmar que atribuíam ao processo natureza publicística.

Todavia, tal incongruência é apenas aparente. Isso porque o que se está aqui propondo é avaliar o Acesso à Justiça apenas pelo viés objetivo de seu conceito. Em outras palavras, se pesquisará objetivamente se os cidadãos portugueses da época das ordenações tinham condições de reivindicar seus direitos mediante os instrumentos a eles postos à disposição.

Não se usará medidas valorativas atuais quanto a esses métodos de resolução de conflitos, fato que poderia trazer um julgamento equivocado quanto aos institutos. Apenas serão tomados como ferramentas de pesquisa os requisitos objetivos do conceito delineado.

Feitos esses esclarecimentos, fixadas as premissas, adotada a metodologia, passa-se à pesquisa e ao estudo propostos.

\section{As ordenações afonsinas}

Tal como fora proposto acima, far-se-á um estudo dedicado a avaliar se as ordenações portuguesas eram monumentos legislativos que aproximavam ou afastavam

\footnotetext{
"Partindo da estrutura do Direito, tal como era traduzido nos comandos objetivos das leis compiladas nas Ordenações, os juristas lusitanos que escreveram suas obras com a atenção voltada mais para a solução das questões práticas, que se apresentavam no cotidiano da vida forense, do que para princípios teóricos, não se preocuparam com a elaboração de um corpo de doutrina acerca daquele direito que regia os atos do processo em juízo. Na copiosa e rica literatura dos decisionistas, comentaristas e praxistas abundam as referências aos casos decididos na Relação e na Casa da Suplicação, bem como as citações dos escritos dos jurisconsultos de renome, ou para invocar-lhes a lição como abono de autoridade, ou para discutir suas opiniões nos casos controvertidos, mas dessa mole de trabalhos jurídicos, redigidos para as mais variadas finalidades, não emergem os postulados teóricos que pudesse ser ordenados dogmaticamente para ensejar a construção doutrinária de uma disciplina jurídico-processual, como novo ramo autônomo do Direito". Cfr. LOBO DA COSTA, Moacyr. Pereira e Sousa e o direito processual. In: Homenagens (Estudos de direito processual), povo gráfica. s.d. p. 69.

10 Apenas a título de curiosidade, não aprofundando a questão por transbordar o tema do trabalho proposto, cita-se que, inobstante a doutrina sempre identificar a obra de BÜLOW como sendo responsável pelo nascimento da ciência processual, cabe apontar o conhecimento de posicionamento destoante. Trata-se de CHIZZINI, Augusto, que afirma: "In questa direzione. Innanzitutto, deve essere sgombrato il campo da un pregiudizio: quello assai diffuso e radicato secondo il quale la moderna scienza processuale sia nata con Bülow e con il suo lavoro sul processo come rapporto giuridico. Nulla è più infondato (...)", atribuindo, mais adiante, a Gönner a obra inicial da autonomia processual. Cfr. Privato e pubblico nella ripartizione dei ruoli processuali: i poteri dell'interveniente adesivo Rivista di Diritto Civile, n. 3, ano XLII, Padova, Mai/Jun, 1996. p. 339-340.

11 Por todos: DINAMARCO, Cândido Rangel. Instrumentalidade do processo. 14. ed. São Paulo: Malheiros, 2009. passim.
} 
os cidadãos da época dos direitos por elas assegurados. Em outros termos, propôs-se analisar alguns institutos pela ótica do Acesso à Justiça, entendido pelos aspectos acima delineados.

Para tanto, far-se-á a análise da primeira compilação de Leis do Reino de Portugal, concluída no ano de 1446, século XV, portanto. São as chamadas Ordenações Afonsinas, nome atribuído pelo fato de ter sido finalizada no mesmo ano em que D. Afonso $\mathrm{V}$ assume o poder.

Antes, porém, de adentrar nas ordenações em si, de avaliar alguns seus institutos individualizadamente, tentar-se-á compor o cenário social, econômico, político e educacional de Portugal do período. Em outras palavras, traçar-se-ão os contornos dos elementos extraprocessuais do Acesso à Justiça.

Começa-se pela estruturação do poder. Portugal via arraigado em suas estruturas o sistema absolutista. O Rei, por vontade divina, tinha o objetivo de tomar medidas dirigidas ao bem comum da sociedade. Para a consecução desses seus objetivos, o monarca deveria ter em mãos como instrumento as leis. É justamente por essa razão que surgem os clamores por uma legislação positiva. ${ }^{12}$

Assim, quanto ao absolutismo visto na época, explica obra coordenada por Sérgio Buarque de Holanda: "de fato, profundo era o sentido da 'própria autoridade, liberdade, livre vontade e poder absoluto', 'de nossa certa ciência e poder absoluto, e por bem o prol comunal de todos', então invocados pelo novo monarca. Correspondiam tais expressões à convicção de se concentrarem em suas mãos todos os poderes, por vontade divina, com o objetivo de tomar as necessárias medidas, visando à realização do bem-estar coletivo. $\mathrm{O}$ instrumento de que serve o rei para dar cumprimento à sua missão é a lei". ${ }^{13}$

Nesse ambiente, D. João I incumbe a João Mendes a tarefa de ordenar a legislação portuguesa. Essa tarefa é confirmada por D. Duarte. Contudo, antes que fosse chegado o fim dos trabalhos, a morte o arrebata, ficando o encargo para Rui Fernandes, que o concluí quando João V era Rei.

12 Nesse sentido: "Sem dúvida, o surto legislativo resultou do reforço de autoridade régia. A difusão dos princípios romanos como "quod principi placuit legis habet vigorem" e "princeps a legibus solutus est" (Digesto, 1. 4. 1 e 1.3. 31), alicerçava poderes públicos ilimitados do monarca nas esferas executiva, judiciária e legislativa. Inicia-se o caminho da centralização política e da relacionada unificação do sistema jurídico. Cada vez mais se iria polarizando no rei a criação do direito, embora, decerto, conhecendo algumas atenuações de ordem prática, designadamente as que decorriam da colaboração das Cortes ou das prerrogativas dos municípios. A lei passa a considerar-se, não só um produto da vontade do soberano, mas ainda uma sua actividade normal”. Cfr. COSTA, Mário Julio de Almeida. História do direito português. 3. ed. Coimbra: Almedina, 2008. p. 257-258.

13 Cf. HOLANDA, Sérgio Buarque de. História geral da civilização brasileira. Rio de Janeiro: Bertrand Brasil, 2010. p. 22. 
Além da monarquia em si, instituição mais importante do absolutismo lusitano, havia como órgão estatal de apoio o Conselho do Rei, formado por membros do clero, nobreza e representantes dos principais centros urbanos, como o Porto, Évora, Lisboa e Coimbra. Sua composição era rotativa. Contudo, tal mobilidade era contrária aos princípios absolutistas imperantes à época, motivo pelo qual esse Conselho foi perdendo importância com o passar dos tempos, chegando a mais intensificada míngua no Reinado de D. Afonso V. ${ }^{14}$

Outrossim, compunham a estrutura política quatrocentista de Portugal as chamadas Cortes que, supostamente, eram o órgão representativo da população lusitana. Contudo, "embora não rareassem os pedidos e as promessas de periodicidade, jamais tais assembleias foram reunidas com regularidade, tendo os progressos do absolutismo determinado, automaticamente, a redução do número de suas convocações". ${ }^{15}$

Tal estrutura política se sustenta sobre uma base social divida entre três Estados: a nobreza, o clero e o terceiro estado, de caráter residual, abarcando desde burgueses até camponeses.

Os nobres, como bem notado em obra dedicada ao tema, foram subjugados aos poderes do monarca. Era dependente do poder central, fato que concentrou poderes nas mãos do rei e determinou uma intensa submissão do primeiro Estado ao governante.

Aqueles que resistiam ao poder real sofriam enérgicas consequências. "De fato, como nos diz Ângelo Ribeiro, 'dos nobres, os mais irrequietos e os mais audazes tinham experimentado os rigores da justiça do rei, aplicada com uma rudeza de tal modo implacável que não haveria memória de rigor semelhante". ${ }^{16}$

Da mesma forma, o clero, inobstante os monarcas portugueses muitas vezes possuíssem a fé católica, também não sujeitava o poder central. O rei utilizou-se bastante do apoio da Igreja de Roma para sua expansão, contudo, seus poderes eram bastante concentrados, seguindo à risca os preceitos absolutistas.

14 Em relato sobre a redução das funções do Conselho do Rei, assim afirmam os estudiosos: "Conforme o exigissem as circunstâncias, variava-se a composição do Conselho, podendo ser convocadas as autoridades reconhecidas em assuntos especiais, bem como pessoas de prestígio e influência. D. Duarte, por sua vez, reduzira a três o número de conselheiros (um infante, um conde e um bispo), mas isto quando o sentido prático do título evoluía para o conteúdo simplesmente honorífico. Já na época de D. Afonso V., este último estágio fora atingido, distinguindo-se, então, a rigor, duas espécies de conselheiros: os que ostentavam a dignidade, mas eram praticamente destituídos de funções, e os que, a critério do monarca, eram chamados a auxiliá-lo a "suportar os trabalhos e encargos do reino". BUARQUE DE HOLANDA, Sérgio. História geral da civilização brasileira. Rio de Janeiro: Bertrand Brasil, 2010. p. 22.

15 BUARQUE DE HOLANDA, Sérgio. História geral da civilização brasileira. Rio de Janeiro: Bertrand Brasil, 2010. p. 23.

16 BUARQUE DE HOLANDA, Sérgio. História geral da civilização brasileira. Rio de Janeiro: Bertrand Brasil, 2010. p. 26. 
O terceiro Estado, por sua vez, era a base de apoio do rei. Manifestavam-se os burgueses por meio da Corte, que, como se disse acima, foi perdendo espaço diante da centralização do poder. Contudo, foi sobre esse estamento que o projeto das grandes navegações foi construído.

Porém, a despeito dessas afirmações, não se pode imaginar que o povo português vivesse em favoráveis condições. Estavam sufocados pela grande quantidade de impostos, fonte de vida do regime monarquista absolutista.

Descrevendo-se as situações fiscais dos cidadãos portugueses, para se ter uma rasa ideia, assim afirmam os estudiosos: "Numeroso eram os impostos a alimentar o erário, dando margem a dizer-se terem eles, em grande parte, contribuído para tolher o desenvolvimento regular do comércio e das indústrias. Destacavam-se as portagens, recaindo sobre mercadorias e objetos trazidos ou levados da terra, cobradas à entrada da povoação; açougagens, pagas pelas reses mortas para fins de alimentação; ochavas, ou oitavas, correspondentes à oitava parte do valor de alguma coisa; tabeliado, pago pelos tabeliães em razão do exercício da sua função; portágio, ou passagem, a ser pago por quem passasse por determinadas terras: mordomado, parcela que, de cada penhora realizada, caberia ao rei; e impostos pagos pelos judeus e mulheres da mancebia. Novidade, na época, foi o desenvolvimento das sisas, regulamentadas por D. Afonso V; ninguém a elas escapava, a menos que se tratasse de fidalgos e homens de armas em guerra, sendo todos obrigados a pagá-las por todas as coisas compradas, vendidas, trocadas ou escambadas, com exceção do ouro, prata e pão cozido". ${ }^{17}$

Ademais, no que tange ao cenário cultural e educacional da época, nota-se, outrossim, uma restrição aos postos de ensinamento. As escolas não eram acessíveis a todos do povo. Via de regra, eram os membros da nobreza que tinham acesso à informação.

Vale ressaltar que mesmo os que possuíam esse acesso, na maioria das vezes, tinham contato com ensinamentos básicos, não sendo ultrapassado o limite dos estudos elementares de gramática e escrita do Latim. ${ }^{18}$

17 BUARQUE DE HOLANDA, Sérgio. História geral da civilização brasileira. Rio de Janeiro: Bertrand Brasil, 2010. p. 29.

18 Essa é a informação trazida por CARVALHO, Rômulo de, que assim expõe a situação do ensino em Portugal: "D. Manuel I também se interessou pela educação da classe nobre. Recordemos que D. Pedro de Meneses, na Oração a que nos referimos, alude a esse caso quando trata dos edifícios novos que o rei mandou construir para o Estudo: 'Nelas' [nas casas], 'além dos costumados estudiosos, também mandou instruir e ensinar rapazes e adolescentes nobres em número difícil de contar, os quais deixam o paço durante o tempo dos estudos, e recebem o costumado soldo e diária que ele liberalmente lhes dá'. Esquecendo o 'número difícil de contar', que faz parte do estilo empolgado do autor, teremos que concluir que, poucos ou muitos, havia jovens fidalgos que eram instruídos no Estudo Geral. As palavras 'além dos costumados estudiosos' revelam que esses 'rapazes e adolescentes nobres' não frequentavam o Estudo como estudantes dele, propriamente ditos. Admitamos que iriam ao Estudo receber os elementares ensinamentos de 'Gramática', ou seja, a leitura e a redaç̧ão, que era o mínimo currículo para quem não pretendesse continuar os estudos. De facto, D. 
Desse modo, mostrando a limitação dos estudos em Portugal, Marcello Caetano afirma que: "Até ao final do século XIII o ensino se fazia nas escolas das catedrais e dos mosteiros, mas apenas para preparar os clérigos. Era estudos particulares, portanto, das corporações que os mantinham e raro iria além dos rudimentos do saber, quando muito do trivium e quatrivium (Gramática, Retórica, Dialética, Aritmética, Geometria, Astronomia e Música). Alguns conhecimentos teleológicos se ministravam também aos futuros clérigos. Mas para estudar a fundo a Teologia, o Direito Civil e o Canónico e a Medicina era preciso ir às escolas estrangeiras, abertas a todos, estudos gerais. O Direito ensinava-se, sobretudo, em Salamanca e em Bolonha; a Teologia em Paris". ${ }^{19}$

Destarte, avaliando as precárias condições do ensino para a grande massa populacional e suas dificuldades econômicas, ${ }^{20}$ presume-se inexistir, pelo menos para a maioria dos cidadãos, os elementos externos ao processo (ou elementos sociais), que são: consciência dos direitos, ciência de como efetivá-los (uso do processo), bem como de condições financeiras para arcar com as custas processuais.

Ora, se nem mesmo sabiam ler e escrever, não haveria, por óbvio, condições subjetivas para se conscientizarem dos seus direitos individuais. Nota-se, em uma primeira análise, que a conjuntura econômica, social e cultural da grande maioria dos portugueses, ${ }^{21}$ no período das ordenações Afonsinas, não tinham os requisitos elementares

Manuel, com intenção de eliminar a ignorância dos moços fidalgo na sua corte esplendorosa, obrigou-os a aprender a ler e escrever o Latim sob pena de lhes retirar o 'soldo e diária"'. (Cf. História do ensino em Portugal - desde a fundação da nacionalidade até ao fim do regime de Salazar-Caetano. Lisboa: Fundação Calouste Gulbenkian, 2008. p. 145). No mesmo sentido, em brilhante tese de mestrado apresentada na Universidade Federal Fluminense, em trabalho dedicado ao estudo do Conde de Casa Melhor e os valimentos em Portugal, CARVALHO GOMES, Vinicius Orlando de, assim expõe sobre os estudos na nobreza ao se referir especificamente a Luís de Vasconcelos e Sousa: "De acordo com um dos seus biógrafos, Luís de Vasconcelos foi educado no colégio Jesuíta de Santo Antão, tendo recebido a educação complementar com um aio escolhido por seus pais. Nesse período, apesar da crescente valorização da cultura letrada, grande parte da nobreza portuguesa não enviava seus filhos à universidade. No entanto, é possível que a exemplo de seu pai cultivasse interesse pelos livros e assuntos políticos". (Cfr. O Conde de Castelo Melhor: Valimento e razoes de Estado no Portugal seiscentista (1640-1667), 2009). Demonstrando ainda essa limitação, CAETANO, Marcello afirma: "por falta de um estudo geral em Portugal muitos homens desejosos de aprender e de entrar no estado clerical desanimam com as despesas e incômodos acarretados pelas longas distâncias a percorrer e pelos perigos a arrostar para irem as partes longínquas frequentas as escolas" (Cfr. CAETANO, Marcello. História do direito português (sécs. XII-XVI). 4. ed. Lisboa/São Paulo: Editora Verbo, 2000. p. 284).

19 CAETANO, Marcello. História do direito português (sécs. XII-XVI). 4. ed. Lisboa/ São Paulo: Editora Verbo, 2000. p. 283.

20 “(...) a Idade Média se ressentiu profundamente de três flagelos clássicos da humanidade: a fome, a peste e a guerra. No reinando de Afonso IV, deflagrou sobre o mundo de então um cataclismo que produziu em toda a Europa as mais vastas e duradouras consequências sociais, económicas e jurídicas: foi a epidemia conhecida pelo nome de peste negra". Cfr. CAETANO, Marcello. História do direito português (sécs. XII-XVI). cit., p. 278.

21 Em interessante estudo sobre a economia portuguesa, inobstante destinado à análise em especial do Século XIII, que extrapola o momento aqui visitado, mas que fornece grandes elementos para o que aqui se quer avaliar. Nota-se que nem mesmo as expectativas de vida do povo lusitano e a mortalidade infantil eram 
para o Acesso à Justiça nos moldes como exposto no início do trabalho, isto é, por uma perspectiva Cappellettiana desse conceito.

Feita essa breve análise inicial sobre os elementos extraprocessuais de Acesso à Justiça nas Ordenações Afonsinas - condições econômicas, políticas, sociais e culturais não muito favoráveis -, passa-se agora à análise dos institutos processuais dessas leis portuguesas, mais precisamente ao Livro III, que trata do processo civil nessas ordenações.

\subsection{Instituições do processo civil afonsino e o acesso à justiça}

Cabe ponderar, antes de mais nada, que todos os títulos 128 títulos das Ordenações Afonsinas poderiam ser analisados pelo olhar do Acesso à Justiça. Entretanto, não é o que aqui se propõe. Além de soar como enfadonho e repetitivo, não teria grande utilidade para os escopos do presente estudo: avaliar se havia institutos que favoreciam o acesso e se haviam outros institutos que obstavam esse acesso. Isso, como se verá, é possível com a análise de apenas alguns títulos.

Dessa maneira, inicia-se a avaliação fazendo-se referência ao parágrafo 5 , título 20 referente à ordem do juízo, do livro terceiro, que assim dispõe:

E os Juizes devem muito trabalhar por trazer as partes a concordia, e efto naõ he de neceffidade, mas de oneftidade e virtude polos tirar de trabalho, omefios, e defpefas; pero nos feitos Crimes, honde feja amoftrado o crime, devem fer punidos, e naõ ficarem fem pena; mas nos outros feitos, que aos Juizes faõ inotos, e o direito das partees nom he a elles certo, affi como he no começo,, devem trabalhar por os concordar; e conclufaõ dos Sabedores he, que nenhuũ nam deve fer muito prompto a litiguar. (3.20.5)

algo não muito animador. Assim afirma: "A doença e a morte eram acontecimentos quotidianos. Apesar das alterações pontuais motivadas pela eclosão de diferentes surtos epidémicos, a característica principal desta variável será sua relativa estabilidade ao longo desses anos, mantendo-se tênue vantagem da vida sobre a morte". E mais adiante, complementa: "Os níveis de mortalidade normal mantiveram-se elevados ao longo da centúria. No entanto, várias condicionantes interferiam e pontualmente alteravam estes indicadores: as diferenças de vida no campo e na cidade, a maior actividade laboral da mulher em certas zonas, desiguais percentagens de jovens, adultos e idosos em determinados universos populacionais e conjuntura políticas e economicamente instáveis". (Cf. GUARDADO MOREIRA, Maria João; VEIGA, Teresa Rodrigues. A evolução da população. In: História económica de Portugal. Lisboa: Imprensa de Ciências Sociais, 2005. p. 48). Assim, também aponta CAETANO, Marcello trazendo dados econômicos e sociais: "A agricultura que seguia a sua tradição dos períodos anteriores, pois é uma actividade que só muito lentamente evolui ou se transforma, sofre profundo abalo quando da grande peste de 1348 (peste negra). A mortalidade desta epidemia desaprovou os campos que, à míngua de quem deles curasse, ficaram em grande parte incultos, perdendo-se também muitas cabeças de gado. Esse abalo da agricultura por escassez de mão-de-obra e translação maciça da propriedade fez-se sentir profundamente durante todo o resto do século XIV" (Cfr. CAETANO, Marcello. História do direito português (sécs. XII-XVI). ob. cit., p. 275-276). 
Em sua primeira parte, como se nota, o legislador português teve como objeto de preocupação a conciliação entre as partes de um processo. Isso se deve, segundo a redação transcrita, porque sobrariam às partes muito trabalho e despesas.

Desse modo, nota-se que o processo das Ordenações Afonsinas era um processo custoso, provavelmente com taxas pesadas e que, ao final, com um desfecho desconhecido, poderá não ter valido a pena litigar.

Em um primeiro momento, a regra pode soar como restritiva ao acesso à Justiça, tendo em vista que "sobrar-lhes-ão muito trabalho, omezios e despesas", se não chegarem a um consenso. De fato, altas custas e elevados gastos consubstanciamse em empecilhos para que a maior parte da população lusitana seiscentista, em sérias dificuldades econômicas, como se viu acima, pudesse reivindicar judicialmente seus direitos.

Ocorre, todavia, que esse problema não passou despercebido pelas ordenações em comento. Mesmo que tais obstáculos estivessem presentes, deveria 'o juiz muito trabalhar para tentar a concórdia'. Nesse aspecto, nota-se que, a despeito de inexistir técnicas capazes de reduzir os custos do processo - ou até eliminá-los, como ocorre com a justiça gratuita atual - há por meio dos poderes do juiz uma tentativa de se evitar a injustiça - ou desnecessidade do final do processo -, realizando assim um acordo.

Tal técnica, além de constatada no processo civil dos dias atuais (art. 331 do CPC), é um eficaz meio de se atingir a justiça no caso concreto. Isso se dá pelo fato de que as partes, cedendo parcialmente em sua pretensão (ou até mesmo sacrificando-a em prol da pretensão alheia) transacionam, chegam a um denominador comum, que se não é a integral felicidade, também não se configura uma derrota e uma perda total do bem da vida.

Nesse ponto, portanto, nota-se uma previsão bastante interessante em favor do acesso atribuído aos cidadãos à Justiça.

Ainda naquilo que concerne às custas no processo previsto nas ordenações, há que se notar que, diante da disposição do parágrafo 2 , título 5, do livro 3 (3.5.2), que dizia que:

\begin{abstract}
"E assr pertence ao Autor deliberar as coufas, ante que comece o feito, as quaes lhe comprem pera aver vencimento delle; porque todo o Autor, que quifer acufar, e demandar, deve-fe aconfelhar com feus amigos, e deliberar com Sabedores, e entendidos fe he bem, e feu proveito fazer a demanda, ou acufação, que quer fazer", estando mais para frente a exigência da capacidade postulatória para propositura da demanda. ${ }^{22}$
\end{abstract}

22 “(...) e ter Procurador, ou Vogado, que feja fabedor, em tal guifa, que ante que comece o feito, feja avifado 
Logo, além de o indivíduo ter que se consultar para que verificasse as chances de existência de seus direitos, coisa que ainda hoje se recomenda, a Lei Afonsina previa a necessidade da presença de um advogado, bem como de uma intensa preparação de provas, de elementos favoráveis, de argumentos, tudo antes mesmo de iniciado o feito, vez que o desfecho incerto pode lhe acarretar "omezios e despesas elevadas" (3.20.5).

Isso, certamente, exigia que a parte interessada na reivindicação de um direito por vias judiciais despendesse dinheiro antes mesmo do contato direto com as estruturas jurisdicionais. Ou seja, antes da própria propositura da ação, os cidadãos já deveriam, por prudência, iniciar seus gastos. Não havendo um procedimento como dos atuais Juizados Especiais atuais, que prescindem de uma preparação técnica, acredita-se que tal previsão favorecia os mais abastados, capazes de arcar com os custos sem prejuízo de sua subsistência, gerando, assim, uma desigualdade de tratamento.

Nesse ponto, portanto, acredita-se que a lei restringe o método judicial de resolução de conflito a uma pequena parcela da sociedade portuguesa, tendo em vista as dificuldades econômicas existentes para a maioria da sociedade e a não-constatação de medidas destinadas a equilibrar essa distorção como visto no dispositivo anteriormente comentado.

Ocorre, porém, que se o legislador afonsino não previu um processo livre de rígidas e custosas preparações prévias, o mesmo dispôs aos jurisdicionados, em contraponto ao procedimento ordinário existente, um procedimento sumário: "o primeiro, solene, formal, escrito; o segundo, cabível nas causas de menor valor, seguia 'sem outro estrépito (sem maiores formalidades), nem figura de juízo, somente sabia a verdade (3.24.1). Este, sem dúvida mais simples e ágil, inspirado na célebre bula de Clemente V, de 1306, concernente aos processos que tinham desenvolvimento de modo 'simpliciter, breviter, de plano, ac sine streptu ac figura iudicii'". ${ }^{23}$

Como afirmado anteriormente, um processo menos formalista tende a ser mais célere. Nesse sentido, como também já citado, o tempo é inimigo da parte menos favorecida economicamente, que muitas vezes depende substancialmente do bem da vida em debate e, consequentemente, da resolução do conflito.

que lhe naõ faleça coufa alguữma. E efta he a caufa, e rezaõ, porque ao Autor nam dam inducias pera deliberar, pois que ante qye comece o feito, deve preparar as coufas, que lhe comprem, e aconfelhar-fe fe tem direito, e fe lhe compre contender, ou feixar, ca o vencimento dos feitos he muito duvidofo, e depois que o começar, e feu adverfario a Juizo trouver, he neceffario prefeguir o feito, e o acabar, fem avendo inducias, ou outros termos para deliberar em effas coufas fufo ditas, e cada huữa dellas aver, ou bufquar, pois de todo o Juizo inftructo deve vir".(3.5.2)

23 AZEVEDO, Luis Carlos de; CRUZ E TUCCI, José Rogério. Lições de história do processo civil lusitano. São Paulo: Revista dos Tribunais, 2009. p. 72. 
Nesse sentido, a disposição desse procedimento sumário menos formal é um facilitador para que os cidadãos busquem a solução de seus problemas por meios judiciais. A celeridade, a facilidade e a deformalização são elementos aptos a favorecer o Acesso à justiça.

Ademais, o fato de o processo ser simplificado faz com que os indivíduos com menor cultura, ou mesmo com menos conhecimento técnico, tenham condições de compreender minimamente o que se passa no feito, quebrando (ou minimizando, pelo menos), a barreira cultural apontada anteriormente, motivo de acanhamento e opressão. ${ }^{24}$

Há que se ressaltar, outrossim, que tal procedimento era previsto para as ações de menor valor econômico, ou seja, justamente aquelas que envolviam a parte mais pobre da população. Corroborando o que fora dito no parágrafo anterior, o acesso à Justiça é bem estruturado pelo legislador no dispositivo 3.24.1 afonsino.

E dizemos, que fe effa demanda for movida fobre força, roubo, guarda, ou condifilho, ou foldadas, em taees cafos, e cada hum delles poderá o Autor forma fua petiçaõ per palavram fem outro efcripto, nom embarguante que paffie a dita contia de trezentos reis branquos, ou tres onças de prata, moftrando loguo o Autor Efcriptura publica de fua tençaõ no cafo da guarda, e condifilho, e foldadas, fegundo forma da Ordenaçaõ sobre ello feita, cini dito he: em taees cafos affy exceptados deve o Julguador proceder fumariamente, fem outro eftrepito, nem figura de Juizo, fomente fabida a verdade, como dito he no feito de pequena contia. (3.24.1)

Ainda no que tange aos procedimentos sumário e ordinário, nota-se mais adiante nas ordenações outro ponto de extremo interesse no que tange à busca da Justiça: a flexibilização do procedimento. Assim diz 3.29.7:

ITEM. Se o Juiz conheceffe d'alguũ feito, sem que fegundo Direito deva proceder fummariamente, em tal cafo averá luguar a Reconvençaõ, fe for de tal calidade, em que fummariamente fe deva proceder. E fe a Reconvençaõ foffe tal, que defejaffe conhecimento hordinario, naõ fe poderia fazer, falvo de o Reo renunciaffe o privilegio da Reconvençaõ, per que he outorguado, que ambas procedam igual paffo, ca emtam bem fe poderia fazer a Reconvençaõ, mas andará cada huữa per feu curfo, a faber a Convençaõ fummariamente, e a Reconvençaõ per via Ordinaria, fegundo forma de Direito.

24 Nesse sentido, Cfr. CAPPELLETTI, Mauro; GARTH, Bryant. Acesso à justiça. Trad. Ellen Gracie Northfleet. Porto Alegre: Antônio Fabris, 2002. p. 24. 
Aqui, o legislador afonsino prevê a possibilidade de o réu abrir mão do procedimento sumário cabível para sua reconvenção e adotar o rito ordinário previsto para a ação. Logo, tem o réu a faculdade de escolher qual o melhor procedimento será adotado para reivindicar seus direitos, sendo, pois, um interessante sinal apontando para um possível acesso à Justiça.

A flexibilização, seja ela na forma, no tempo, na sequência da produção dos atos ou na estruturação geral do procedimento, é algo hoje bem visto por alguns doutrinadores, ${ }^{25}$ mas combatido veementemente por outros tantos. ${ }^{26}$ A legislação processual portuguesa atual, no art. 265-A, inspirador do dispositivo 107 do anteprojeto de CPC brasileiro, possui a previsão de flexibilização do procedimento. Entretanto, mostra que o debate atual já contava com apontamentos nas ordenações afonsinas.

Embora sem a consciência técnica que permeia a hodierna discussão, acredita-se a flexibilização adotada é apta ao favorecimento de um acesso à Justiça. ${ }^{27}$

Saindo do campo da propositura da ação e do procedimento a ser adotado, passa-se agora a analisar brevemente as decisões e os recursos existentes nas ordenações afonsinas e seus reflexos sobre o acesso à Justiça.

Segundo se nota, havia três tipos de decisão no processo afonsino: a) as sentenças definitivas; b) as chamadas sentenças interlocutórias com força de definitivas; e c) as meras sentenças interlocutórias.

As primeiras, com força permanente, eram as atuais sentenças de mérito, capazes de resolver a crise apresentada pelas partes. Essas, pela sistemática das ordenações em análise, eram passíveis de impugnação por meio da apelação.

As chamadas sentenças interlocutórias com força de definitiva eram aquelas que, se proferidas, impediam que juiz proferisse a decisão de mérito. Equipara-se, portanto, às atuais sentenças terminativas. Pode-se inferir isso dos exemplos trazidos pelo 3.72.6, que diz dá-se essa sentença quando "o demandador nom he peffoa pera demandar", isto é, em termos atuais, quando o autor é carecedor da ação por ilegitimidade de parte. Contra esse tipo de sentença cabe a mesma apelação.

E assy em todallas outras coufas femelhantes, em que nam pode já mais fer hordenado proceffo per aquelle Juiz, que a Sentença deu per a dita citaçam, affy que nam pode vir

25 GAJARDONI, Fernando da Fonseca. Flexibilização procedimental: um novo enfoque para o estudo do procedimento em matéria processual. São Paulo: Atlas, 2008. passim.

26 Ernane Fidelis dos Santos afirma que eventual alteração na ordem dos procedimentos "ofende diretamente o princípio do devido processo legal (art. $5^{\circ}$, LIV, da CF) (...)", cf. SANTOS, Ernane Fidelis dos. Dos procedimentos especiais do código de processo civil. Rio de Janeiro: Forense, 1999. v. 6.

27 Nesse sentido, em sede de tese de láurea defendida pelo autor do presente trabalho, ver: RIGUETTI, Gabriel Felipe Roqueto. 2011. Poderes gerenciais do juiz: flexibilização procedimental e efetividade do processo. Tese (Láurea) - Faculdade de Direito. Universidade de São Paulo, São Paulo. passim. 
a Sentença Defenitiva, por a qual poffa fer corregida a dita Interlucutoria por o Juiz d'appellaçam, fe da dita Defenitiva foffe appellado: ou fe per ventura foffe o Feito, fobre que he dada Sentença Interlucutoria á execuçam, ante que venha a Defetniva, affy como fe o Juiz julgua, que metem alguũ a tornamento; ca em todos eftes cafos fobreditos, e em todos os outros a elles femelhantes, Mandamos que feja recebida a appellaçam da Sentença Interluccutoria, fe a parte appellar quifer, porque o dapno, que a parte por ella recebeffe, nom fe poderia cobrar pela Definitva: ou que o Feito he de tal natura, que depois da dita Interlucutoria nom pode vir a Defenitiva, ou fe vir pode, nom fe poderia já mais recobrar o dapno, que jaa foffe feito por a execuçam da Interlucutoria feia ante da Defenitiva, affy como parece polos exemplos fufos ditos, e a elles femelhantes. Que nam podem todollos Feitos, em que efto acontecer, fer contheudos em efta Noffa Ley, mas os Juizes devem proceder de femelhavel a femelhavel. (3.72.6)

Por outro lado, as sentenças interlocutórias não eram apeláveis. Contudo, segundo José Rogério Cruz e Tucci \& Luiz Carlos de Azevedo: “Ao contrário, porém, das sentenças definitivas, podia o juiz revogar o decreto interlocutório, fosse de ofício, fosse a requerimento da parte. Neste último caso, se mantida a decisão, tirava o interessado o ‘estormento' por se sentir agravado, redigido pelo tabelião, ou 'carta testemunhável', pelo escrivão (3.77)", ${ }^{28}$

Nota-se, por sua vez, que o legislador vislumbrou a possibilidade de erro do juiz, predispondo aos jurisdicionados recursos como método de correção, seja a apelação, seja o estormento ou carta testemunhável. Nessa toada, embora tenha havido a restrição recursal quanto às interlocutórias - restrição que pode ser notada nos dia atuais (Lei n. 9.099/95) -, as ordenações afonsinas trazem esse receio do erro e, por consequência, da injustiça.

${ }_{28}$ Cfr. AZEVEDO, Luis Carlos de; CRUZ E TUCCI, José Rogério. Lições de história do processo civil lusitano. São Paulo: Revista dos Tribunais, 2009. p. 79. Também sobre o Título 77, Marcello Caetano: "O título 77, redigido em estilo legislatório, ocupa-se das dificuldades opostas pelos juízes recorridos que não querem receber as apelações e agravos das partes. Quando a parte agravada pedia ao tabelião ou ao escrivão o instrumento do agravo ou a carta testemunhável, com frequência o juiz em vez de limitar a inserir no documento a sua resposta ao recurso, mandava transcrever todo o processo «para darem tão grandes custas às partes que antes deixam de seguir essas apelações e agravos que pagarem as ditas custas». As Ordenações determinam que o juiz recorrido deve responder logo ao agravo «declarando na dita resposta aqueles autos do processo somente que pertencem a esse agravo», para tudo ser exarado no documento, que incluirá também a réplica do apelante, tudo sob a fé do tabelião ou do escrivão. Se o juiz se recusasse a dar resposta, o tabelião ou o escrivão dariam ao apelante o instrumento ou carta contendo o traslado dos autos do processo que ele requeresse para mostrar como era agravado (§5)" (Cfr. CAETANO, Marcello. História do direito português (sécs. XII-XVI). cit., p. 587-588). 
Dessa forma, diante dessa breve análise, crê-se que esse monumento legislativo, ao prever a possibilidade de recursos, privilegiou medidas que favorece o acesso à Justiça.

Há ainda que ressaltar que havia a Casa da Justiça, que acompanhava o rei em sua deambulação pelo reino. O fato de o monarca sair do enclausuramento de sua morada e andar pelas terras da coroa, fazia com que, embora minimamente, tomasse contato com a realidade social, política, econômica e cultural, podendo ter uma perspectiva mais próxima da realidade. Não se pode afirmar que as decisões por ele proferidas eram mais justas por causa da andança. Todavia, acredita-se que esse contato poderia criar condições para embeber de justiça a solução do caso.

Ademais, pinçando um outro instituto das ordenações afonsinas, faz-se remissão à chamada restituição por inteiro, prevista no livro 3 , título 55 , parágrafo 6 , que diz:

E todo efto, que dito he, Dizemos que nam aja lugar em aquelle, que quer desfazer a Sentença definitiva per via de reftituiçam, dizendo que era meior de vinte e cinco annos, ou abfente per cauza da Reepubrica ao tempo que contra elle foi dada, ou per alguuma outra jufta rezam, que Fe chama em Direito Claufula Jeeral; Ca em taees cafos como eftes jeeralmente poderá bem aleguar a Excepçam peremptoria depois da Sentença defenitiva.

Segundo explicam os professores Tucci e Azevedo, tal exceção peremptória traz como exemplo de aplicação da restituição do bem ao menor no tempo do fato (incapaz, portanto) e ao ausente por estar servindo a República em outro sítio - sendo ambos exemplos clássicos romanos -, bem como àquele que apresentasse uma cláusula que parecesse justa ao magistrado (cláusula geral), mesmo depois do trânsito em julgado da decisão.

Nesse sentido, quanto ao primeiro exemplo trazido pelas ordenações afonsinas, parece ser de extrema justiça a flexibilidade da coisa julgada diante da incapacidade da parte. Assim, se não consciente, a lei parece trazer uma presunção de hipossuficiência capaz de maleabilizar a rigidez da técnica para favorecer a justiça.

O mesmo ocorre com o ausente por motivos oficiais, segundo exemplo da lei. Indo além das situações clássicas, o legislador português ainda previu uma cláusula aberta, possibilitando que novas situações que apareçam concretamente, se justas, também possam flexibilizar a coisa julgada.

Nota-se aqui uma busca pela justiça, dando azo a abertura de caminhos ao acesso à Justiça.

Por fim, pinçando um último instituto das ordenações em análise, agora já no campo da execução, faz-se menção ao disposto no 3.92.2. 
A qual ley vifta per Nós, declarando acerqua della Dizemos, que quando o Porteiro fefer alguuma execuçam per noffa Carta, ou Sentença de alguum noffo Julguador, nom feja nenhuum tam oufado que lho contradigua per força, e aquelle, que lho forçofamente contradiffer, feja prefo, e apenado, afsy como aquelle, que contradiz o Mandado d'ElRey; e pero fe elle tal peffoa for, que nam deva por ello rezoadamente fer prezo, afsy como fe for Cavalleiro, ou Fidalguo de Solar, em tal cazo feja emprazado, que a certo dia pareça per peffoa perante Nós: a effe que o emprazar envie a Nós todo o auto, que ouver paffado fobbre o dito tolhimento e efcripto per Tabalian publico, em tal guifa que poffamos compridamente fer emformados deffe feito como fe paffou, pera todo vermos, e fazermos o que for Direito. E quando effe, contra que for feita a execuçam, entender que he feita como naõ deve, recorer-fe-há ao Julguador que a manda fazer, e alegue perante elle as rezoeẽs e embarguos, que ouver a fe na fazer, e defembargue feu feito por Direito, que força lhe nam deve fer confentida.

Perceba que há previsão de que a ordem da execução do julgado não poderia ser contradita, sob pena de severas punições àquele que assim o fizesse. Nesse sentido, parece que o legislador privilegiou a efetividade da execução, buscando não dar margem a debates delongados sobre algo já debatido em processo de conhecimento.

Entretanto, na segunda parte desse dispositivo legal, vislumbra-se exceção: o cavaleiro ou fidalgo, que ao invés das penas, eram conduzidos a juízos para as medidas de direito. ${ }^{29}$

Ora, claro é o privilégio trazido pela ordenação a determinados sujeitos, privilégios esses que certamente feriam a igualdade de indivíduos e impunha óbices ao acesso à Justiça.

\section{Conclusão}

Do breve estudo feito, tentou-se traçar algumas considerações sobre as circunstâncias sociais, políticas, econômicas e culturais de Portugal na época das ordenações Afonsinas.

Viu-se que as precárias condições educacionais, as crises econômicas, bem como a pouca participação popular nos rumos da monarquia absolutista lusitana, eram empecilhos para que os cidadãos buscassem a reivindicação de seus direitos pela via do processo judicial.

29 AZEVEDO, Luis Carlos de; CRUZ E TUCCI, José Rogério. Lições de história do processo civil lusitano. São Paulo: Revista dos Tribunais, 2009. p. 83. 
A justiça, diante dessas barreiras identificadas pelo professor italiano Mauro Cappelletti, faziam do método judicial de resolução de conflito, ao que parece, algo não acessível a todos.

Contudo, no âmbito interno do processo, buscou-se ressaltar institutos da fase de propositura da ação, da fase de conhecimento, dos recursos, das exceções peremptórias e da execução, de variadas naturezas, portanto, demonstrando que, independentemente de haver consciência do legislador na feitura da lei, o processo afonsino traz inúmeras previsões progressistas, capazes de viabilizar um efetivo acesso à Justiça. Alguns momentos, todavia, impõem obstáculos capazes de diminuir esse acesso ou até mesmo inviabilizá-lo.

Acredita-se que essa oscilação, ora favorecendo, ora impondo empecilhos, é fruto de uma não consciência do processo como ramo autônomo do direito. Somado ao fato dos portugueses seiscentistas não encararem o direito processual como uma ciência, e, portanto, não desenvolverem técnicas apropriadas, o acesso à Justiça não poderia ser um escopo dessa legislação.

A despeito disso, nota-se uma sensibilidade bastante interessante do legislador, que, inobstante ignorância quanto à técnica, inúmeras vezes tentou contornar as deficiências do objeto por intuição de justiça.

São Paulo, fevereiro de 2013.

\section{Referências}

AZEVEDO, Luiz Carlos de; CRUZ E TUCCI, José Rogério. Lições de história do processo civil romano. São Paulo: Revista dos Tribunais, 1996.

BUARQUE DE HOLANDA, Sérgio. História geral da civilização brasileira. Rio de Janeiro: Bertrand Brasil, 2010.

CAETANO, Marcello. História do direito português (sécs. XII-XVI). 4. ed. Lisboa/São Paulo: Editora Verbo, 2000.

CAPPELLETTI, Mauro; GARTH, Bryant. Acesso à justiça. Trad. Ellen Gracie Northfleet. Porto Alegre: Antônio Fabris, 2002.

CARVALHO, Rômulo de. História do ensino em Portugal: desde a fundação da nacionalidade até ao fim do regime de Salazar-Caetano. Lisboa: Fundação Calouste Gulbenkian, 2008.

COSTA, Mário Julio de Almeida. História do direito Português. 3. ed. Coimbra: Almedina, 2008.

CRUZ E TUCCI, José Rogério; AZEVEDO, Luiz Carlos de. Lições de história do processo civil romano. São Paulo: Revista dos Tribunais, 1996. 
DINAMARCO, Cândido Rangel. Instrumentalidade do processo. 14. ed. São Paulo: Malheiros, 2009.

GAJARDONI, Fernando da Fonseca. Flexibilização procedimental: um novo enfoque para o estudo do procedimento em matéria processual. São Paulo: Atlas, 2008.

GOMES, Vinicius Orlando de Carvalho. O Conde de Castelo Melhor: valimento e razoes de Estado no Portugal seiscentista (1640-1667), 2009. Dissertação (Mestrado).

GUARDADO MOREIRA, Maria João; VEIGA, Teresa Rodrigues. A evolução da população. In: História económica de Portugal. Lisboa: Imprensa de Ciências Sociais, 2005.

LOBO DA COSTA, Moacyr. Pereira e Sousa e o direito processual. In: Homenagens (estudos de direito processual). São Paulo: Editora Povo Gráfica, s.d.

MADEIRA, Hélcio Maciel França. A história do direito. Disponível em: < http://helciomadeira. sites.uol.com.br/historia_arquivos/hd001.htm>.

RIGUETTI, Gabriel Felipe Roqueto. Poderes gerenciais do juiz: flexibilização procedimental e efetividade do processo. 2011. Tese (Láurea) - Faculdade de Direito, Universidade de São Paulo, São Paulo.

SANTOS, Ernane Fidelis dos. Dos procedimentos especiais do código de processo civil. Rio de Janeiro: Forense, 1999. v. 6.

VEIGA, Teresa Rodrigues; GUARDADO MOREIRA, Maria João. A evolução da população. In: História Económica de Portugal. Lisboa: Imprensa de Ciências Sociais, 2005.

VON BÜLOW, Oskar. Privato e pubblico nella ripartizione dei ruoli processuali: i poteri dell'interveniente adesivo. Rivista di Diritto Civile, n. 3, ano XLII, Padova, Mai/Jun, 1996. 